\title{
Research on the Design of Enterprise Salary System based on Data Mining Technology
}

\author{
Xiaoyue Guan ${ }^{1}$, Bo Yang ${ }^{2}$ \\ ${ }^{1}$ Yinxing Hospitality Management College of CUIT, Sichuan, Chengdu, 611743 \\ ${ }^{2}$ Sichuan Academy of Social Sciences, Sichuan, Chengdu, 610000
}

Keywords: Data Mining, Salary System, Enterprise Management

\begin{abstract}
At present, it is difficult to deal with a large amount of data, and it is more difficult to find the intrinsic factors influencing the salary design from these large numbers of data. So, modern enterprise pay design process to face a large number of complex information and data, and data mining technology in dealing with large amounts of data has a unique advantage. In this paper, the data analysis process in salary design is the main line, and how to analyze and deal with the data mining techniques such as classification, clustering and association rules and It provides strong decision support for pay design.
\end{abstract}

\section{Introduction}

Data mining is a new discipline in the 1980s. With the rapid development of computer technology and the growing popularity of database technology, the rapid expansion of information formed by the information explosion of the ocean almost everyone needs to face the problem, a direct result of the "rich data but the lack of knowledge" phenomenon. In order to make better use of these data, data mining technology came into being and it can analyze the massive data, from which to find the existence of specific patterns of law, for the decision support to provide a strong The knowledge of the information. Data mining technology has a wide range of applications, has been in securities, banking, telecommunications, insurance, retail, medical and other fields have been applied. In the enterprise human resources management, data mining technology has also been applied to assess department performance, employee performance, monitoring subsidiaries or department financial fraud. At present, it is difficult to deal with a large amount of data, and it is more difficult to find the intrinsic factors influencing the salary design from these large numbers of data. Based on the actual process of enterprise salary design, this paper puts forward the application model of data mining technology, and studies several application methods of data mining technology at different design stages, and tries to dig out the valuable intrinsic information from the large amount of data information faced by salary design Association and rules.

\section{Problems in Enterprise Salary System}

Enterprise salary system is the highest authority of the enterprise to discuss the business through a certain period of future business decision-making and target planning financial data description and liability constraints based on it is the modern enterprise organization using modern management theory and methods in the scientific business forecasting and decision-making Based on the strategic objectives of the enterprise, market-oriented, operating profit as the goal, to cash flow as the center, for a certain period of time enterprise funds acquisition and delivery, the income and expenditure, business results and their distribution and other financial activities To carry out the planning and planning operation, to ensure that the financial management objectives to achieve effective management mechanism. Enterprise salary system management system through continuous development has formed a more perfect system structure. At present, the financial budget is mainly profit budget, cash flow budget, asset and liability budget. However, there are still some problems in the enterprise salary system.

In the preparation of financial budget, most companies still use the traditional fixed budget, regular budget and other methods. This static compilation method makes the budget indicators 
remain constant during the execution process, which is more applicable to enterprises with little fluctuation in business volume. When the enterprise sales, price, cost and other factors have changed greatly, the static budget is blind, lagging and lack of flexibility. Therefore, enterprises should actively seek a scientific and reasonable way to strengthen the dynamic management.

Some enterprises in the financial budget, mainly based on historical indicators and past activities, combined with the level of capital, technology and management to develop future financial budget targets. In this way, often overlooked on the external factors of the detailed analysis and prediction, making a lot of financial budget indicators difficult to adapt to the external environment, which is difficult to implement in the enterprise. Therefore, enterprises in the financial budget should not only consider the internal factors, but also to consider external factors, such as market share, customer profitability, etc., in order to determine the range of sales or price changes in the range, the final formation of flexible budget.

In large enterprises, because each business to take a separate database system, the lack of contact between the data, it is likely to cause the emergence of data silos. Data silos make the data of the same thing because of the different source and the lack of contact between each other, resulting in the integrity of the data is not high. The existence of this limitation makes the financial management system unable to provide complete and accurate financial budget information to the decision-making department. Therefore, enterprises should use the development of information technology with the development of data over the years to summarize and analyze the situation for high-level decision-making use.

\section{The Enterprise Salary System Application Data Mining Technology Necessity}

Data mining includes data collection, data processing, data transformation, data mining, pattern evaluation, knowledge representation of several processes, the first four processes are a cycle of repeated process, in the process of repeated the mining results to assess and modify, Until you find the real result. Data collection is through extensive collection of user information, the establishment of the necessary database for data mining to prepare. Data processing is to inject the information into the denoising and other operations, so as to ensure that the data can really reflect the object to be excavated. Data conversion is to denoise the data to a certain format conversion, to adapt to the data mining system or data mining software processing requirements. Data mining refers to the use of a variety of data mining methods can be used separately to analyze the data, dig out the user needs a variety of rules, trends, categories, models and so on. The model assessment evaluates the found rules, trends, categories, and models to ensure the correctness of the patterns found. The knowledge representation is to present the excavation results in front of the user in a visualized form.

Data mining technology is characterized by: data mining technology is a user-oriented search model, it can automatically extract the relevant data between the valuable knowledge, and the knowledge in a visual, dynamic way to the user feedback. Data mining can automatically process a large number of raw data in the database through the pre-set algorithm, and use various methods and means to extract the necessary and meaningful patterns from a large amount of data, dig out the specific relationship between the objects, Need answers to questions for decision making.

In the information enterprise, the enterprise salary system should not only use the computer to replace the manual completion of data processing, but should use its financial data management at the same time, and on this basis to help senior management and financial management of high-level decision making. As the financial budget data is distributed in various departments of the enterprise, the amount of financial budget data from various departments is gradually increasing as the size of the current enterprise expands, and the classification of the departments involved is becoming more and more detailed. The financial information is not easy to be unified Is a long-standing problem in the enterprise. Therefore, a number of departments for many years of financial data summary and analysis have become one of the major financial management needs. In the process of gradually advancing the information, the number of employees in the enterprise has the demand for equipment, etc. It has undergone great changes, in which the expansion of the existing data and the 
original data extraction work, will give the financial budget department a lot the work pressure. Therefore, the financial budget department hopes to be able to deal with the increasing complexity of data in a concise and flexible manner and to generate corresponding reports.

\section{Realization of Data Mining Technology in Enterprise Salary System Model}

The decision tree method is applied to the enterprise salary system. The decision tree can be used to classify the data according to the instance to a known class set to classify the various budget data. You can also classify the data set through the decision tree. The Data link is to predict the future. The decision tree is created by recursively dividing the instances into subgroups. Each partition is based on a property test of the instance and that is, using some conditions to determine how the data set should be split. The specific process is: first find the most discriminatory factors, the data is divided into multiple subsets, each subset and select the most discriminatory factors to be divided, until all the sub-only contains the same and enterprise salary system users The purpose of different, then the focus of the enterprise salary system requirements will be different. At this time for the management of business groups of enterprise salary system providers, faced with complex information needs side, also increased the cost of enterprise salary system provided.

The demand state of enterprise salary system itself is multi-level. Information demand is the information consumer demand and ability of consumer information products and services, enterprise salary system needs with the information needs of the potential, effectiveness, relevance of the three characteristics, so the enterprise salary system needs are divided into three levels: the potential demand state The state of demand that is evoked; the state of demand that is recognized.

Enterprise salary system needs more than the characteristics of the diversification, multi-level state, the user multi-level, making the use of enterprise salary system object is not clear. In the case of enterprise salary system needs are not clear, the enterprise salary system providers to provide the principle of what to bring them a problem, but also for the provision of enterprise salary system to choose the content of the free space, but also produced a disclosure of enterprise salary system overload Or lack of. For the enterprise salary system needs, because the provision of enterprise salary system is to face different needs, and then because of different enterprise salary system needs of different target, so enterprise salary system needs to identify enterprise salary system, in the process of screening enterprise salary system need to pay cost. Obviously through the decision tree model we can classify employees to find out which types of employees are dissatisfied with existing pay levels and which types are satisfactory. Based on this classification information, we can easily know the types and characteristics of the employee groups that are dissatisfied with the pay in the firm, and analyze the factors that are likely to trigger employee discontent and make reasonable design and adjustment.

\section{Conclusion}

Data mining is a promising application and challenging new disciplines, in the information and industrial production has been widely used, and achieved significant economic and social benefits. China's work in this area is mainly concentrated in the field of academic and information technology, business management practice is starting. With the continuous development of data mining technology, the gradual improvement of the domestic enterprise management system and the extensive application of the database, the application of data mining technology will pay for the salary, performance as the core of human resources management and the whole enterprise management bring great benefits.

\section{References}

[1] Xie Li Shan, Zhang Yan, Ling Qi. Enterprise salary system in the era of knowledge economy [J]. Journal of Sun Yatsen University, 2002 (06)

[2] Guo Yulin. Knowledge staff incentive efficiency analysis [J]. Contemporary Finance, 2002 (11) 
[3] Wu Liangping. High-tech small and medium-sized enterprise knowledge management [J]. Contemporary Finance, 2002 (11)

[4] Kuang Suxun. The internal equity of pay and external competitiveness [J]. Technical Economics, 2002 (06)

[5] Song Jingjin. Enterprise salary management and business risk [J]. Finance and Economics Theory and Practice, 2002 (03)

[6] Zhang Jing. Use of remuneration to support the company's high-speed growth - IT industry salary design core [J]. Science and Science and Technology Management, 2002 (04) 